\title{
Histórias contrafactuais: o surgimento da Física Quântica
}

OSVALDO PESSOA JR.

\section{Histórias contrafactuais da Ciência}

$\mathrm{E}$ XISTE um consenso de que a história da ciência poderia ter sido diferente, já que muitos fatores fortuitos afetam o desenvolvimento de qualquer área científica. Sendo assim, quais outras histórias de ciência teriam sido possíveis?

O historiador normalmente se afasta deste tipo de pergunta, já que não existe uma maneira direta de investigar histórias "contrafactuais", ou seja, histórias possíveis que não se realizaram. Alguns historiadores têm se dedicado a esse tipo de "história imaginária", mas o consenso na área, conforme salientado por E.H. Carr, é que tais “jogos de salão”, apesar de logicamente corretos, não constituem o modo de discurso da História (ver Hawthorn, 1991: 1-9).

No entanto, a história da ciência (mais do que as histórias de outras áreas) apresenta uma forte restrição em seu desenvolvimento: os cientistas do passado trabalhavam em busca de fenômenos, leis e teorias "objetivos", que hoje nós conhecemos, mas que eles ainda não conheciam, apesar de ser justamente a busca por estas leis que dirigia seu trabalho (Hund, 1966: 23). Com a vantagem do retrospecto ( hindsight), nós temos condições de avaliar o quão distantes diferentes cientistas estavam da descoberta de um novo princípio e, assim, avaliar o que poderia ter acontecido se um evento fortuito (um acidente mortal, por exemplo) tivesse impedido que um cientista (como Max Planck) descobrisse um novo princípio (a quantização da energia).

Antes de atacarmos o problema de como construir histórias contrafactuais plausíveis, examinemos qual seria a utilidade de se fazer isso. Para que histórias contrafactuais? A motivação principal é tentar reavivar a área da filosofia da ciência conhecida como "teorias de dinâmica científica", que teve seu auge na década de 70 com os debates envolvendo Kuhn, Lakatos, Laudan etc. (ver uma resenha em Laudan et al., 1993) (1). Tratava-se de uma tentativa de fazer uma "ciência da ciência". Analisaremos adiante algumas razões da degenerescência desse programa de pesquisa, mas notemos aqui que se a pretensão é fazer uma ciência do desenvolvimento científico, 
então a noção de causa é central (assim como é em qualquer ramo da ciência).

Ora, em qualquer ciência, a noção de "causa" que precede um efeito traz implicitamente uma indicação da possibilidade que se atualizaria (ou seja, do estado de coisas que ocorreria) caso a causa não ocorresse. Se dizemos que a causa do aquecimento da pedra é a presença do sol, implicitamente estamos dizendo que na ausência do sol, a pedra permaneceria fria. Qualquer afirmação sobre causa pode ser traduzida numa afirmação sobre contrafactuais (ver discussão em Lewis, 1973). Analogamente, a noção de causa nas ciências históricas só pode ter função explicativa se se tiver uma idéia das histórias possíveis que não se concretizaram. Se as histórias contrafactuais da ciência pudessem ser mapeadas, poder-se-ia explicar melhor por que os diferentes episódios da história da ciência ocorreram (2).

Retornando agora a uma questão levantada acima: por que as teorias de dinâmica científica deixaram de ser progressivas? A razão principal parece ser a dificuldade de testar e selecionar as diferentes propostas. As teses dessas metateorias eram bastante gerais, e sempre era possível encontrar exemplos históricos que satisfizessem uma metateoria em particular. A excitação inicial provocada pelo debate entre as diferentes metateorias estimulou muito a pesquisa em história da ciência, de forma que não é por falta de dados empíricos (históricos) que as metateorias não têm avançado. $\mathrm{O}$ que parece estar faltando, além de um maior detalhamento das teorias de dinâmica científica, é uma concatenação mais exata entre a profusão de dados históricos e as previsões dessas metateorias. E essa concatenação só poderá ser obtida mediante o uso de computadores.

No presente projeto, utilizamos uma linguagem de inteligência artificial, Scheme (um casamento de Lisp com Algol 60), para armazenar informações históricas e para rodar programas que extraiam informações relevantes para o mapeamento de histórias contrafactuais. Nesse sentido, o projeto se enquadra na tradição da filosofia-da-ciência computacional que surgiu na década de 80 (ver, por exemplo, Thagard, 1988).

\section{Histórias contrafactuais da Física Quântica}

O estudo de caso escolhido foi o surgimento da Física Quântica Velha, a partir da segunda metade do século XIX. A primeira grande descoberta rumo à Mecânica Quântica foi a da quantização de energia, feita por Max Planck em dezembro de 1900. Ele chegou a este avanço na tentativa de explicar os dados experimentais de Lummer \& Pringsheim e de Rubens \& Kurlbaum a respeito do espectro de radiação de corpos aquecidos (em es- 
pecial, do chamado "corpo negro", que absorve toda radiação incidente), partindo da Mecânica Estatística de Ludwig Boltzmann e dos trabalhos de Willy Wien.

Alguns autores são da opinião de que o caminho trilhado para a descoberta da quantização de energia através da radiação do corpo negro foi “improvável", tendo dependido da genialidade dos cientistas mencionados. Segundo esta opinião, se Planck tivesse escolhido uma outra profissão, muito provavelmente a Física Quântica teria se iniciado a partir de um campo diferente que o da radiação térmica.

Quem publicou a respeito de histórias possíveis da Física Quântica foi o físico e historiador Friedrich Hund (1966), que trabalhava em espectroscopia na década de 20. Em seu pequeno estudo, ele esboçou um punhado de caminhos possíveis para se chegar a diferentes fases de desenvolvimento da Teoria Quântica (3). Apesar das várias sugestões que ele oferece de caminhos históricos contrafactuais, seu estudo não é sistemático e não abarca toda a gama de trabalhos realizados na época, especialmente os experimentais.

O que pretendemos neste trabalho é justamente analisar de maneira mais detalhada a história da ciência do período, de forma a poder postular diferentes histórias contrafactuais e colocar tais especulações em bases mais firmes e detalhadas. O ponto de partida é o armazenamento no computador de informações históricas sobre artigos publicados entre 1850 e 1915, destacando as idéias e avanços de cada artigo e quais trabalhos anteriores influenciaram a publicação de cada artigo. No presente trabalho restringimonos à informação obtida a partir da literatura secundária, especialmente dos livros de Jammer (1966), Mehra \& Rechenberg (1982) e Brush (1976). Isso impõe certas limitações, mas a preocupação maior nesta fase de trabalho é:

(i) estabelecer uma metodologia adequada ao estudo das histórias contrafactuais,

(ii) armazenar as informações históricas e escrever programas computacionais que possam fazer pesquisa na base de dados,

(iii) estudar as novidades conceituais que possam surgir da presente metodologia, como a noção de "avanço", as classes de tipos de avanços e os tipos de influência causal.

Mais adiante apresentamos nossas conclusões preliminares sobre as histórias contrafactuais da Física Quântica, que são um pouco mais detalhadas que as sugeridas por Hund, mas padecem de um mesmo problema 
fundamental: a pouca informação sobre o desenvolvimento da técnica experimental. Esta informação é importante para avaliarmos o quão cedo as descobertas empíricas envolvidas nas diferentes histórias possíveis poderiam ter sido feitas. Pretendemos corrigir esta limitação ao darmos continuidade ao trabalho, examinando as fontes primárias, de forma a obter resultados mais detalhados e fiéis aos acontecimentos históricos.

É importante ressaltar que vários autores já vêm empreendendo estudos histórico-filosóficos detalhados sobre o desenvolvimento de tradições em ciência experimental, mantendo acesa a chama dos estudos de dinâmica científica mencionados acima. Após os trabalhos de Hacking, Franklin, Galison e outros, nos anos 80 , podemos mencionar alguns mais recentes que se aproximam do nosso, com sua preocupação em estabelecer redes de influências históricas e em classificar diferentes tipos de atividade científica. Holton, Chang \& Jurkowitz (1996) fazem uma excelente análise histórica baseada em citações, delineando os antecedentes da descoberta da supercondutividade a altas temperaturas em 1986. Hentschel (1997) utiliza diferentes diagramas para descrever seqüências de estratégias de pesquisa para resolver um problema em Física Solar (ele traz uma boa bibliografia sobre a filosofia da ciência experimental).

\section{Avanços e sua rede de influências}

Para facilitar a leitura deste artigo, apresentarei aqui aspectos gerais da metodologia desenvolvida, deixando para o Apêndice algumas considerações mais detalhadas.

Ao escrever artigos científicos, os cientistas normalmente deixam claro quais foram as influências pertinentes que receberam, e isso é feito por meio de citações. Essas influências podem ser consideradas "causais", já que envolvem eventos do mundo real e a ausência (contrafactual) de uma das influências resultaria em um artigo diferente (ou até na inexistência do artigo, para influências causais fortes). Enfim, é possível ligar os diferentes artigos de um período através dessas influências causais, estabelecendo uma rede de influências entre artigos. Na figura 1 , apresentamos uma rede de influências entre artigos para a área de Radiação Térmica.

No entanto, como estamos interessados em postular histórias contrafactuais, não nos é muito relevante estabelecer qual artigo influenciou qual outro. O importante para nós são as idéias, os dados experimentais e outros "avanços" contidos nos artigos, que iremos supor que também (em sua maioria) estariam presentes em histórias contrafactuais (já os artigos e os cientistas envolvidos poderiam variar de uma história para outra). Assim, o 
aspecto fundamental do método é estabelecer uma rede de influências causais entre "avanços". A figura 2 apresenta a rede de influências entre avanços no caso da Radiação Térmica, que reflete a rede entre artigos apresentada na figura l. Os diferentes tipos de influência causal (representados na figura por setas de diferentes tipos) serão descritas mais adiante.

Os avanços, então, são o termo (meta)teórico fundamental na presente abordagem. Há avanços teóricos, como idéias, formulações de problemas, leis e explicações, constatações de semelhanças e de distinções, reconhecimento de motivações, comparação entre dados e teoria etc. E há também avanços mais experimentais, como a obtenção de dados, o desenvolvimento de técnicas experimentais etc. Um “avanço" não é necessariamente um passo positivo, na direção correta, conforme sugerido pelo significado usual do termo. Para nós, os avanços são as unidades que são passadas de cientista para cientista, são os elementos que são adicionados ao conjunto de idéias, dados, leis, informações, conhecimentos tácitos etc., disponíveis para um certo cientista em uma época específica. Cada cientista assimila um conjunto de avanços, seleciona alguns, rejeita temporariamente outros, combina dois ou mais avanços etc. Segundo nossa visão, a ciência evolui a partir desses avanços disponíveis e dos novos avanços imaginados ou descobertos pelos cientistas teóricos e experimentais. Tal concepção é próxima a de algumas correntes da chamada Epistemologia Evolucionária (ver Hull, 1988: 434).

No entanto, salientamos que os avanços são também as unidades que se conservariam na passagem de uma história possível para outra. Após determinar um conjunto de avanços concatenados em uma rede de influência para a história factual, passamos a postular histórias contrafactuais imaginando ordenamentos diferentes para os mesmos avanços. Naturalmente, novos avanços também deverão ser postulados para diferentes histórias (4).

Os avanços apresentados na figura 2 são apenas uma amostra dos em torno de 350 avanços anotados até aqui neste estudo. Três outras redes de influência importantes correspondem às áreas de Espectroscopia, Efeitos Ópticos e Calores Específicos (sua representação, porém, não cabe neste artigo). Para postular as histórias contrafactuais que desembocam na Teoria Quântica Velha utilizamos, aqui, estratégias intuitivas, a serem descritas adiante. Como prosseguimento do trabalho, pretendemos tornar tais estratégias mais rigorosas, com o auxílio da computação. Além de ser fundamental para a postulação de histórias contrafactuais, o estudo dos avanços também é interessante por si mesmo, apresentando um retrato original da ciência e de seu desenvolvimento, conforme veremos a seguir. 


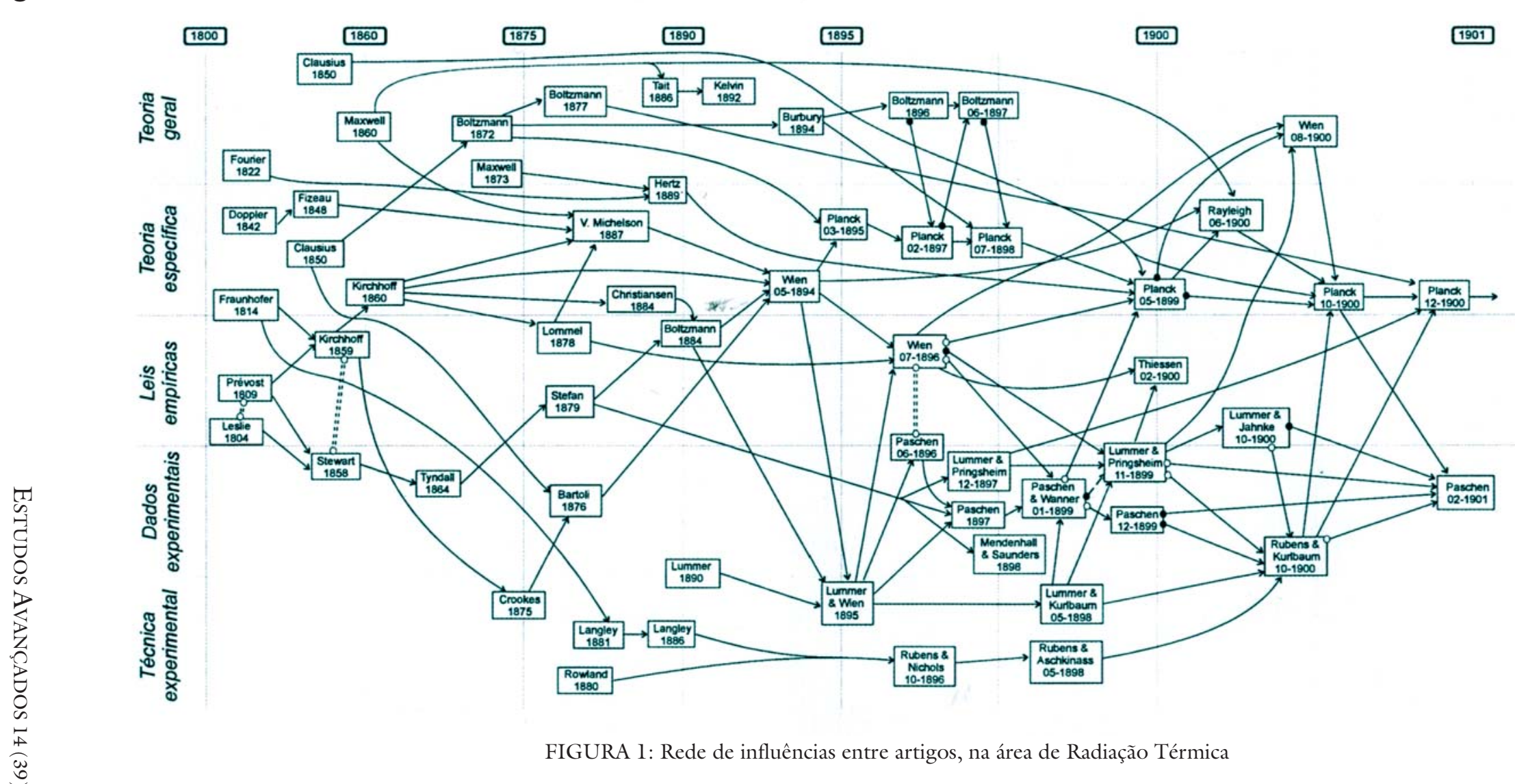




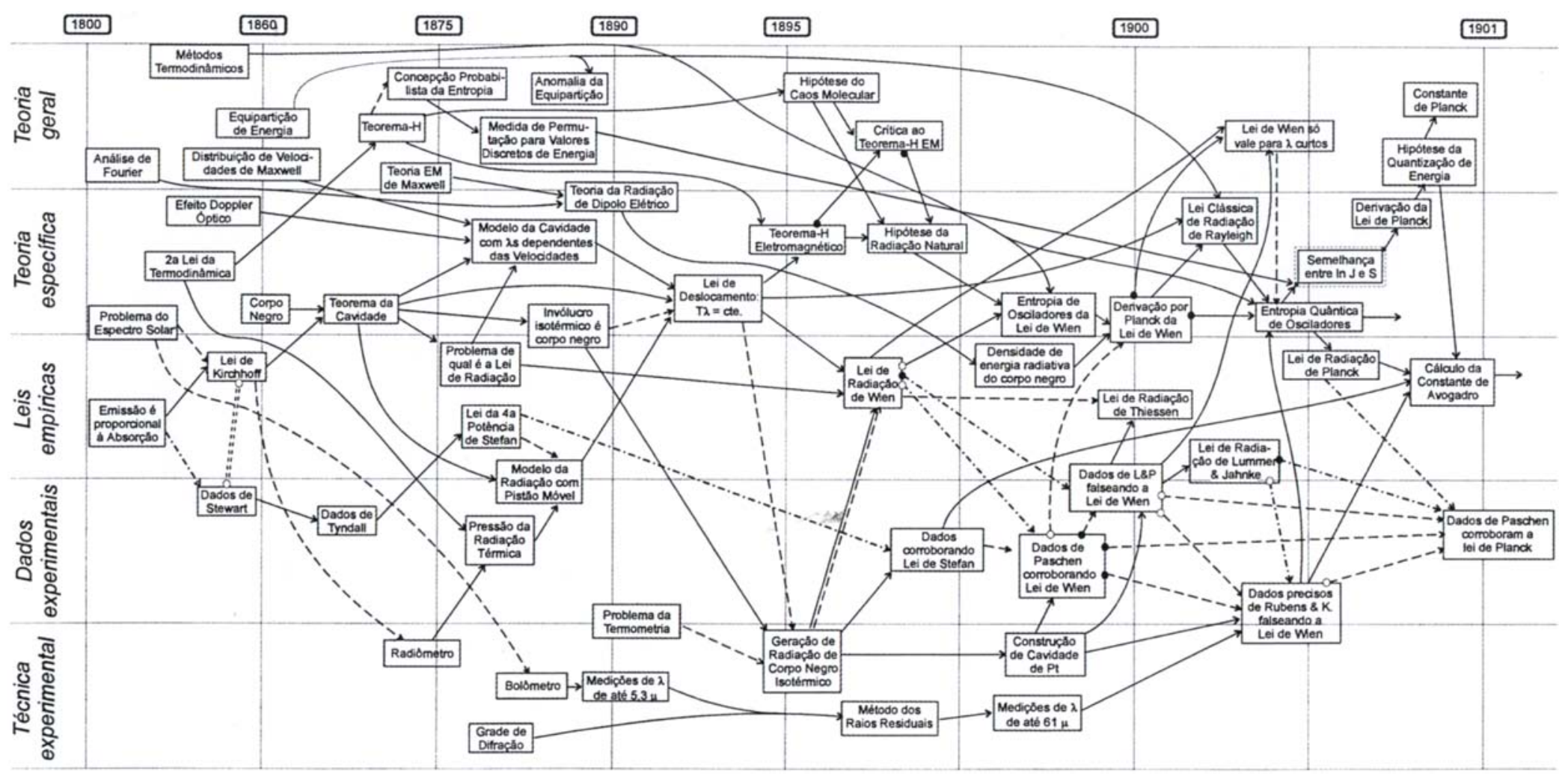

FIGURA 2: Rede de influências entre avanços, na área de Radiação Térmica 


\section{Tipos de avanços}

A presente abordagem à dinâmica científica pode ser considerada um pouco mais “empírica” (ou bottom-up, para usar um jargão computacional) que as abordagens tradicionais. Este traço se manifesta claramente na questão de quais são os tipos de avanços. Examinamos caso a caso os quase 350 avanços que consideramos relevantes, encontrados a partir da literatura secundária, e fomos encaixando-os em diferentes tipos. Encontramos cerca de 60 tipos, que por sua vez podem ser agrupados em dez "classes" de tipos. As relações que aparecem entre esses tipos refletem aspectos da estrutura da ciência.

Na rede de avanços da figura 2, dividimos os avanços grosseiramente em cinco classes gerais (TÉCNICA EXPERIMENTAL, DADOS EXPERIMENTAIS, LEIS EMPÍRICAS, TEORIA ESPECÍFICA e TEORIA GERAL) ao longo do que podemos chamar de "eixo realidade-teoria".

Este eixo R-T aparece no ultrapassado "modelo do bolo de camadas" da ciência (Feigl, 1970), em que a realidade é representada em baixo e a teoria em cima (buscando refletir a realidade), e regras de correspondência fazem a ligação entre ambas. No caso da figura 2, não colocamos em baixo a realidade a ser representada pela teoria científica, mas sim as manipulações da realidade feitas pelos cientistas com seus artefatos experimentais, geradores de dados empíricos.

As classes de tipos de avanços que propomos são um pouco mais detalhadas que a divisão grosseira ao longo do eixo R-T mencionada acima, e estão esquematizadas na figura 3. O eixo R-T vertical se mantém, de forma que em baixo desenhamos a TÉCNICA EXPERIMENTAL e OS DADOS EXPERIMENTAIS. No alto, o DESENVOLVIMENTO DA TEORIA descreve o crescimento e falecimento de teorias, ao passo que o TRABALHO TEÓRICO consiste na atividade do cientista teórico de aplicar métodos formais para a derivação de resultados e previsões. Imbricado nestas duas classes está a classe dos CONCEITOS \& DEFINIÇOEES, que formula os objetos teóricos a serem trabalhados pelo cientista teórico.

No campo entre teoria e dados experimentais colocamos as LEIS \& FATOS, que fazem uma descrição do mundo, podendo também ser considerados objetos da teoria. Já a atividade de comparação entre teoria e experimentação é colocada em uma classe à parte, a da COMPARAÇÃO DADOS-TEO$R I A$, representada na figura como linhas tracejadas que costuram diferentes aspectos da teoria e da experimentação. Paralelamente à descrição fornecida pelas leis, colocamos a classe das EXPLICAÇÕES. Além disso, boa parte dos 
avanços consistem no reconhecimento de problemas, que podem surgir em qualquer uma das classes mencionadas, sendo então desenhadas na figura 3 como bolinhas escuras. Juntamos aos problemas também tipos de avanços que consistem de críticas, formando assim a classe de PROBLEMAS \& CRíTICAS. Por fim, a classe das MOTIVAÇOEES \& VALORES permeiam toda a atividade científica. Um exemplo do tipo de avanço que chamamos MotivaÇão é a constatação feita em torno de 1911 de que a Teoria Quântica era importante (5).

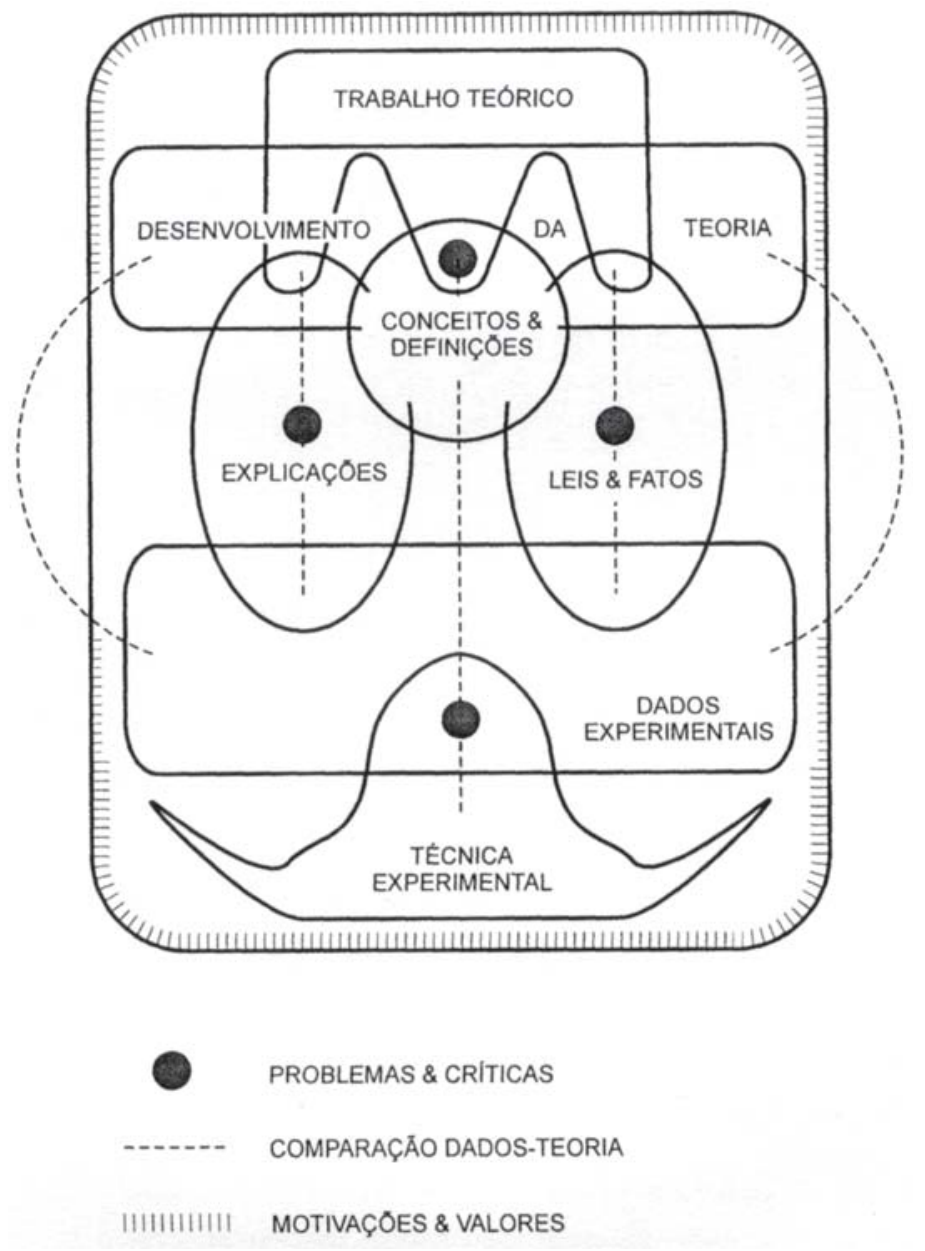

FIGURA 3: A “face da ciência”, representando as classes de tipos de avanços. 
Uma descrição de todos os tipos de avanços propostos não caberia neste artigo, então meramente os listamos no Apêndice (quadro 4). Aqui esmiuçaremos apenas duas classes, com seus respectivos tipos de avanços. A classe denominada DESENVOLVIMENTO DA TEORIA é apresentada na figura 4, consistindo em um resumo geral da evolução das teorias, que certamente deverá ser melhorado no futuro. Cada quadrado apresenta um tipo de avanço, e as setas correspondem mais ou menos às setas apresentadas no desenho de uma rede de influências entre avanços (figura 2), ou seja, representam um movimento temporal, uma relação de antecedência ou uma relação de causa e efeito.

Normalmente encontramos primeiro uma TEORIA RUDIMENTAR, que pode ou não se transformar em uma TEORIA GERAL. A partir desta teoria geral, obtêm-se explicações teóricas, que são aplicações da teoria ou versões específicas da teoria (este tipo de avanço também faz parte da classe das EXPLICAÇÕES).

Antes de continuar, notemos que os tipos de avanços estão dispostos ao longo de dois eixos: na vertical, o eixo R-T já mencionado, e na horizontal o eixo do sucesso do avanço, que no caso de teorias corresponde a um grau de aceitabilidade (no caso de dados e técnica experimental, o sucesso corresponderia mais a um grau de confiabilidade).

Voltando agora aos tipos de avanços da figura, é freqüente ocorrer uma EXTENSÃO DA TEORIA, exemplificado pela introdução de elétron feita por Lorentz na teoria geral eletromagnética, o que certamente pode ser considerado um sucesso da teoria. Outro avanço em direção a um maior sucesso é a AMPLIAÇÃO DE DOMÍNIO, ao passo que seu contrário é a RESTRIÇÃO DE DOMÍNIO.

Esta classe de DESENVOLVIMENTO DE TEORIA é o objeto preferido das teorias de dinâmica científica que mencionamos anteriormente, e seu refinamento em nosso estudo deverá ser feito posteriormente levando-se em consideração estas diferentes (meta)teorias.

A distribuição dos tipos de avanços em relação a dois eixos nem sempre é factível. Para todas as classes, é possível dispor (mesmo que grosseiramente) os tipos de avanços ao longo do eixo R-T vertical, mas muitas vezes a distribuição horizontal nada significa. O segundo exemplo de tipos de avanços são aqueles incluídos na classe de LEIS \& FATOS, apresentado na figura 5. As setas indicam o caminho que geralmente é trilhado na ciência física do período, partindo-se de fatos observados ou inferidos, e desenvolvendo-se leis e princípios mais gerais. 


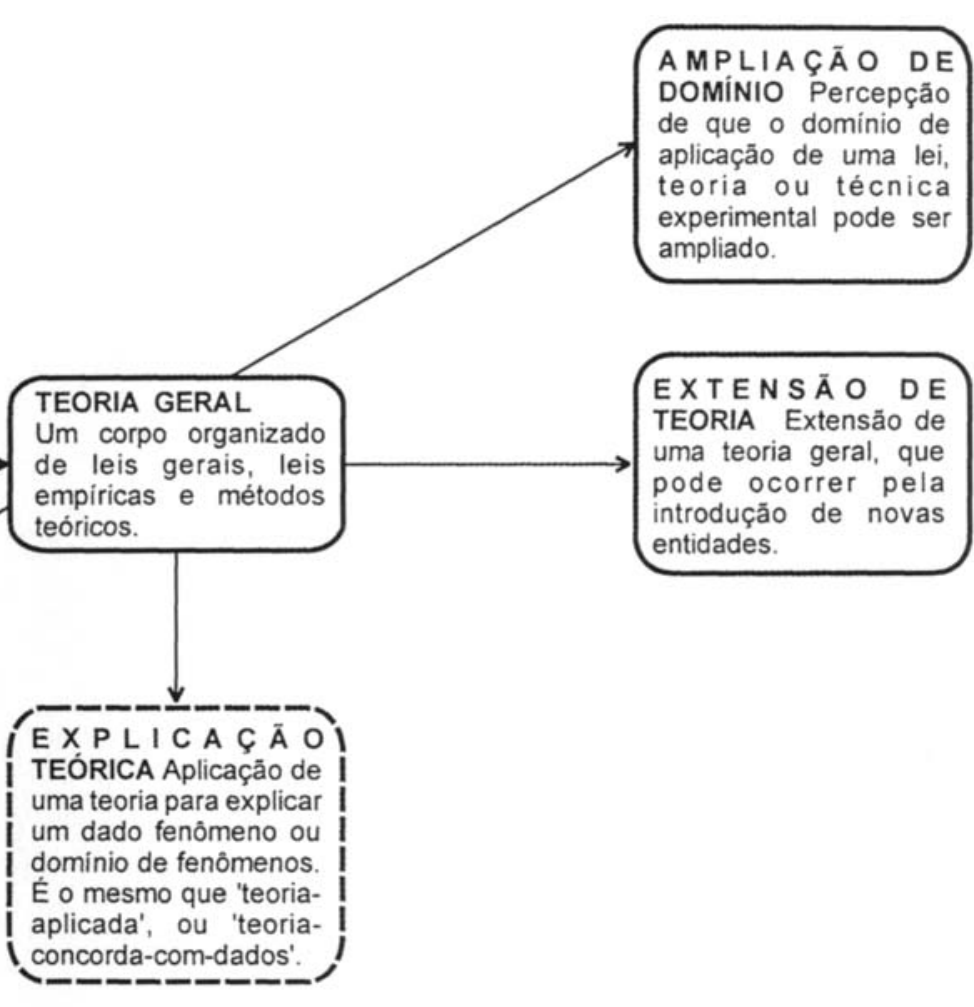

FIGURA 4: Tipos de avanços da classe de Desenvolvimento de Teoria. 


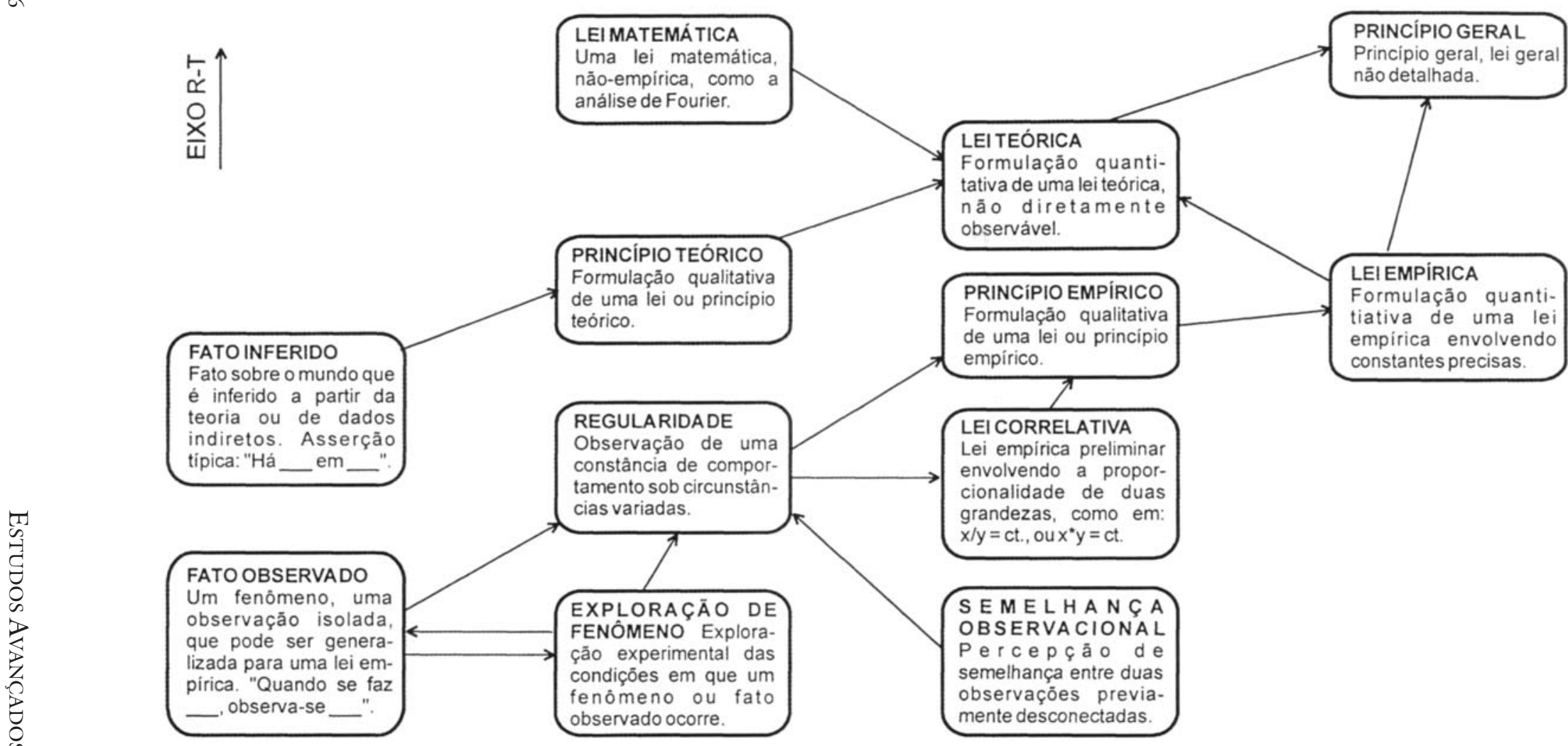

FIGURA 5: Tipos de avanços da classe de Leis \& Fatos. 


\section{Tipos de influência causal}

Nas redes de influência entre avanços, como o da figura 2, é importante diferenciar tipos de influência causal. Afinal, um avanço $A$ que seja necessário (junto com outros avanços) para que surja o avanço $B$ estabelece uma relação qualitativamente diferente do caso em que $A$ apenas contribui circunstancialmente para o surgimento de $B$. Para o estudo de histórias contrafactuais, o primeiro caso é mais importante que o segundo.

Com isso, temos a distinção fundamental entre dois tipos de influência causal.

- Influência forte. Na figura 2 , uma seta cheia $A(\varnothing B$ descreve a situação em que a ocorrência de $B$ só foi possível devido a ocorrência anterior de $A$, dentro de um certo contexto. Em outras palavras, $A$ é condição necessária para $B$ (se $B$ ocorreu, então $A$ ocorreu previamente). Para ilustrar a importância do contexto, tomemos um exemplo de Planck. No contexto em que ele se encontrava (o da Radiação Térmica), a hipótese da quantização de energia só pôde surgir devido à descoberta anterior da fórmula quântica para a entropia dos osciladores. Mas isso não significa que aquela hipótese não poderia ter surgido a partir de outro contexto histórico, contrafactual (como o dos Calores Específicos dos Sólidos). Devemos também lembrar que em geral múltiplas causas fortes e fracas são responsáveis pelo aparecimento de um avanço.

- Influência fraca. Uma seta tracejada $A--\varnothing B$ descreve a situação em que $A$ precede e influencia a ocorrência de $B$, mas não é uma condição necessária para a ocorrência de $B$. Em outras palavras, $B$ poderia facilmente ter ocorrido sem a presença de $A$, mas, mesmo assim, o fato é que $A$ teve uma influência na descoberta de $B$.

A demarcação entre esses dois tipos não é sempre clara. No entanto, enquanto não dispusermos de uma maneira simples de estimar a "força” de uma influência causal, manteremos esta distinção grosseira entre influências fortes e fracas.

Além desta distinção “quantitativa” entre tipos de influência, há também distinções "qualitativas", que dependem das classes de avanços sendo conectadas causalmente. Boa parte das influências anotadas em nosso estudo pode ser considerada forte. Por exemplo: um resultado teórico que seja condição sine qua non para que um princípio seja derivado; um avanço técnico-experimental que seja fator determinante para a observação de um novo fenômeno. Contudo, há relações (entre tipos de avanço) que são qualitativamente diferentes destas. 
Um exemplo importante é a relação que existe entre uma lei empírica e dados experimentais que confirmam ou desconfirmam esta lei (na figura 2 este tipo de influência é representado por uma seta com pontos e traços: $A-\varnothing B)$. Em que medida podemos dizer que uma lei $A$ "causa" a obtenção de dados $B$ ? Muitas vezes, a inexistência (contrafactual) de $A$ levaria à não existência de $B$. No entanto, a obtenção de dados empíricos relevantes pode ocorrer de maneira exploratória, sem ser causado pela postulação prévia de uma lei no mesmo domínio. Em outras palavras, mesmo que reconheçamos que a lei $A$ influenciou fortemente os dados $B$, é sempre plausível postular uma história contrafactual em que $B$ foram obtidos sem a existência prévia de $A$.

Outro exemplo é a relação existente entre uma tese teórica e sua crítica. Em geral, não se concebe uma crítica sem a existência prévia da tese sendo criticada. Há uma relação aí que lembra a causa material aristotélica.

Para finalizar, devemos considerar a questão de se as relações entre os avanços não seriam relações lógicas ao invés de relações causais materiais. Com isto, tocamos na velha distinção entre contexto da descoberta e contexto da justificação. Enquanto "cientistas da ciência", estamos preocupados com as causas para o surgimento de avanços (o que envolve todo o ambiente social e psicológico dos cientistas), com o contexto da descoberta. No entanto, os cientistas são seres razoavelmente racionais, que após suas descobertas costumam elaborar um contexto de justificação, que envolve a conversão das causas materiais (a que estamos nos referindo neste trabalho) em relações lógicas ou teóricas. Dessa forma, a ordem dos fatos se transforma, com certas modificações, na ordem das razões.

\section{Estratégias para a postulação de histórias contrafactuais}

Após o levantamento de uma rede de influências causais entre avanços, pode-se aplicar algumas estratégias intuitivas simples para visualizar diferentes histórias possíveis. Essas estratégias foram usadas até aqui de maneira intuitiva, mas nosso objetivo na continuação do trabalho é torná-las mais rigorosas, mediante rotinas computacionais.

a) Uma primeira estratégia é a suposição de que um avanço aparentemente “improvável” não tivesse ocorrido. Este é o caso da descoberta da quantização de energia, quando imaginamos que Planck não tivesse se tornado um físico. No item $d$ sugerimos um desdobramento desta situação.

b) Outra estratégia bastante simples é a suposição de que um avanço retrospectivamente "provável”, como o desenvolvimento de uma técnica ex- 
perimental, tivesse ocorrido antes do tempo. Que conseqüências isso traria para a "competição entre histórias possíveis"?

c) Em um nível mais restrito, envolvendo apenas poucos avanços (ao contrário das longas cadeias de avanços envolvidas nos itens anteriores), existe um método bastante seguro de estabelecer histórias alternativas. Trata-se da identificação de descobertas independentes. Com esta expressão entendo avanços iguais ou semelhantes que se deram de maneira independente um do outro (como é o caso do desenvolvimento dos aviões pelos irmãos Wright e por Santos Dumont). Descobertas independentes ocorrem em maior número do que tendemos a suspeitar. Elas estão representados nas redes de influência entre artigos (figura 1) por meio de bolinhas brancas ligadas por linhas duplas tracejadas. Na figura 1 , vemos que Paschen chegou, de forma empírica, a praticamente a mesma lei derivada por Wien.

Tais situações são muito importantes para a análise de histórias contrafactuais. Nestes casos, podemos dizer com segurança que se Wien não tivesse chegado à sua lei em 1896, este avanço teria sido divulgado para a comunidade científica por outras vias: no caso, pelo caminho percorrido por Paschen. Às vezes, um cientista está prestes a obter um avanço, quando recebe a notícia de que outro cientista já conseguiu. Neste caso não se fala em descoberta independente, mas tal situação é tão relevante para a análise de histórias contrafactuais quanto uma descoberta que de fato se deu de maneira independente.

d) Ligado ao item (a), é possível formalizar uma estratégia que supõe que a conseqüência de uma descoberta fundamental (na história factual) tenha sido (numa história contrafactual) a causa desta descoberta. Esta estratégia é exemplificada na figura 6 . Se um avanço fundamental $E$ foi alcançado mediante uma história $H_{1}$ (envolvendo avanços $A, B, C, D$ ), e de $E$ derivou-se (juntamente com $F$ ) uma lei $G$, talvez possa-se estabelecer uma história contrafactual $\mathrm{H}_{2}$ que desemboque em $E$ por meio de $G$, envolvendo também $D, F$ e um avanço novo (simbolizado na figura por “?”).

No exemplo apresentado, ao invés da história factual trilhada pela radiação térmica, ter-se-ia uma história contrafactual percorrida através dos calores específicos a baixas temperaturas. Se tal esquema for plausível, ele deverá ser facilmente simulável no computador. Um passo importante, porém, que não envolve uma análise meramente mecânica, é estabelecer a plausabilidade do avanço contrafactual simbolizado por "?". 

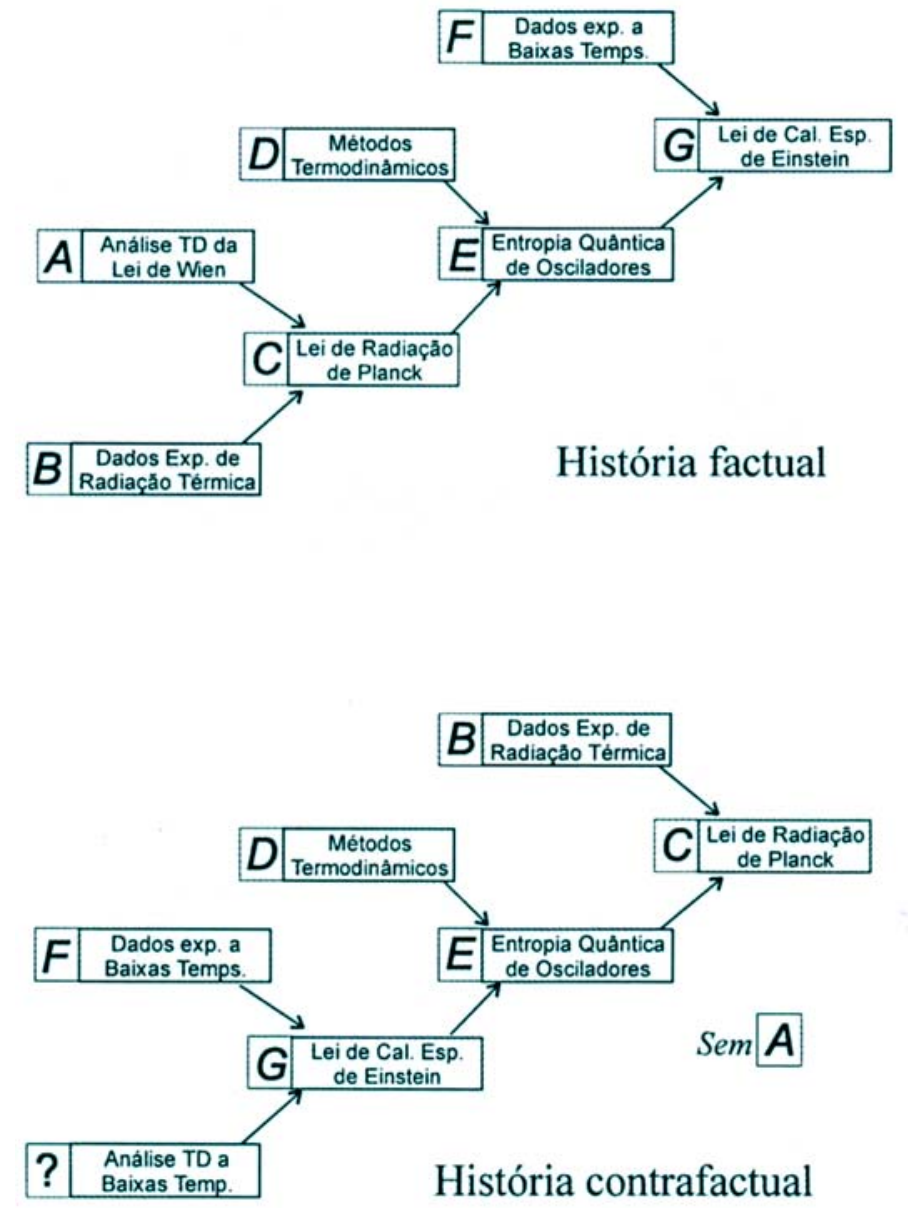

FIGURA 6: Estratégia para postulação de uma história contrafactual.

\section{As histórias possíveis da Física Quântica}

Após considerarmos aproximadamente 350 artigos, e um número quase igual de avanços, pudemos vislumbrar algumas histórias contrafactuais do surgimento da Física Quântica Velha. Identificamos quatro grandes vias e seis pequenas vias, sendo que duas destas não levariam ao postulado quântico (quantização de energia), mas diretamente à dualidade onda-partícula (as ondas de matéria). As grandes vias e algumas das pequenas estão representadas de maneira simplificada na rede de influências entre artigos da figura 7. Omitimos os detalhes de todas as redes por falta de espaço. 


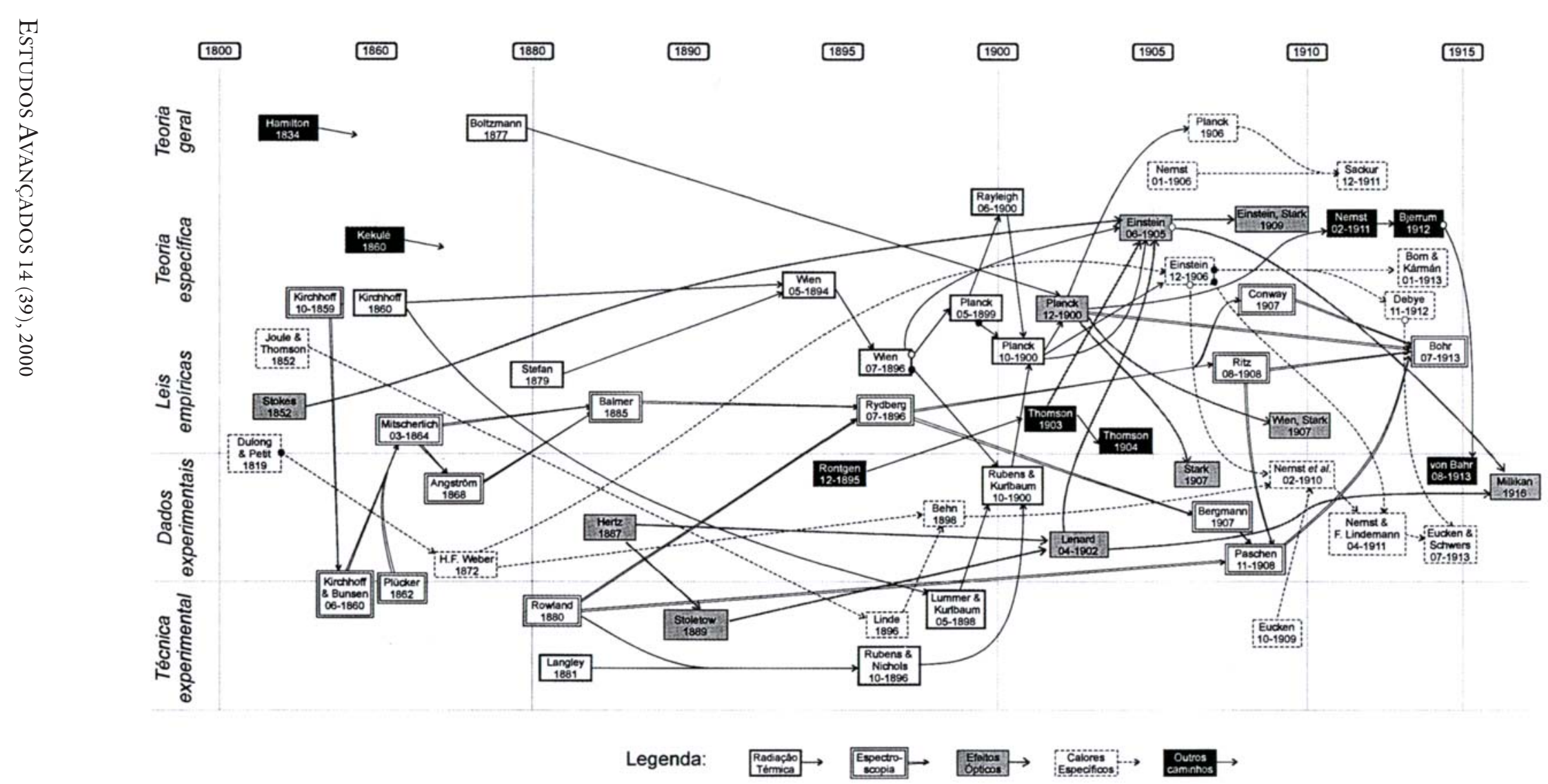

FIGURA 7: Rede de influências entre artigos levando aos primórdios da Física Quântica Velha. 
1 Descoberta da quantização de energia por meio da Radiação Térmi$c a$. Este foi o caminho de fato trilhado historicamente, representado nas figuras 1 e 2. O papel desempenhado por Planck foi crucial. Em outubro de 1900 ele apresentou sua Lei de Radiação, que pode ser considerada uma lei genuinamente quântica. Até este ponto, podemos considerar o caminho trilhado como bastante provável. O que pode ser considerado bastante improvável foi a descoberta da hipótese de quantização de energia para explicar esta lei, descoberta feita em dezembro de 1900. Planck chegou a esta hipótese ao perceber uma semelhança formal entre uma expressão para entropia por ele obtida e uma fórmula publicada por Boltzmann em 1877, fórmula esta que supunha um número discreto de elementos de energia. Planck era um gênio que repousava sobre ombros também geniais: Boltzmann e Wien, do lado teórico, Lummer e Rubens, do lado experimental.

2 Descoberta da quantização por meio da Espectroscopia. Hund sugeriu que este seria o caminho mais provável para se chegar à Física Quântica. O ponto crucial neste desenvolvimento foi a formulação da lei de combinação de Ritz (1908) junto com a percepção de que cada átomo só poderia emitir uma linha espectral por vez (1907). É possível especular que tais avanços já poderiam ter ocorrido em torno de 1890 (Rydberg formulou o princípio de combinação em 1900 mas não ressaltou sua importância). Na continuação de nosso trabalho, tentaremos avaliar a possibilidade desta história contrafactual. Mas, supondo que ela tivesse ocorrido, que conclusões a respeito da natureza discreta do átomo poderia ter sido sugerida? Não tenho ainda condições de avaliar se de fato alguma propriedade quântica poderia ter sido descoberta independentemente dos outros caminhos. Outro ponto a ser salientado é o conceito de quantização da energia rotacional, que levou Bjerrum (1912) a prever linhas espectrais eqüidistantes no infravermelho, confirmadas experimentalmente no ano seguinte (ver figura 7). Se tal observação tivesse sido realizada antes de 1900, seria possível postular-se uma quantização de energia nas moléculas?

3 Descoberta da quantização ou da dualidade onda-partícula por meio de Efeitos Ópticos. Em 1905, Einstein derivou a hipótese do quantum de luz. Apesar de influenciado pela hipótese quântica de Planck, a derivação de Einstein partiu diretamente da Lei de Radiação de Wien (1896) e da expressão correspondente para a entropia dos osciladores (derivada por Planck em 1899). Ou seja, seria possível que Einstein chegasse à hipótese do quantum de luz mesmo que Planck não tivesse publicado nada sobre quantização. Com seu resultado, Einstein ex- 
plicou três efeitos conhecidos: o efeito fotoelétrico, aspectos granulares da fotoionização e a regra de fluorescência de Stokes (estabelecida em 1852 e não explicada pela teoria ondulatória da luz). O efeito fotoelétrico, por si só, já teria permitido a derivação de uma hipótese de quantização: a lei fotoelétrica já era conhecida em 1902, após os trabalhos de Lenard, e foi explicada também por Stark (1907) com base na hipótese da quantização de Planck. $\mathrm{O}$ aspecto granular do raio $\mathrm{X}$, que aparecia no fenômeno da fotoionização, já tinha levado J.J. Thomson em 1903 a propor uma estrutura descontínua para a radiação eletromagnética! Em suma, apenas com base em efeitos ópticos, encontramos três caminhos plausíveis para se chegar à natureza corpuscular da luz (e no passo seguinte, à dualidade onda-partícula para a luz), dois deles independentes da hipótese de quantização de Planck. Resta estudarmos como o progresso experimental nessas áreas se comparava com o caso da radiação térmica, para avaliar a possibilidade de o experimento de Millikan (1916), que confirmou precisamente a lei fotoelétrica de Einstein, ter sido efetuado na década de 1890.

4 Descoberta de uma lei quântica por meio dos Calores Específicos. A partir de 1872 havia evidência de que a lei clássica de Dulong-Petit para os calores específicos dos sólidos, explicada por meio do princípio de equipartição de energia, não funcionava para temperaturas mais baixas. A obtenção de uma lei empírica na qual os calores específicos tendessem a zero no zero absoluto (de temperatura) já poderia ter ocorrido desde então, e tal lei poderia constituir uma lei genuinamente quântica, como foi a lei de Einstein de 1906. Notemos porém que neste trabalho Einstein não precisou utilizar a hipótese de quantização de energia, mas apenas a expressão para a entropia quântica dos osciladores, obtida por Planck também em dezembro de 1900. Parece então que seria mais provável obter uma lei quântica para calores específicos do que para radiação térmica (recordemos a discussão da figura 6). Resta saber se seria tão fácil partir da Lei de Einstein e chegar na quantização de energia quanto sair da Lei de Radiação de Planck e chegar na quantização.

Além dessas grandes vias, reconhecemos também um conjunto de "pequenas vias", que seriam possibilidades com uma menor probabilidade de ocorrer (6).

5 Descoberta da dualidade onda-partícula por meio do Raio X. A natureza dual do raio $\mathrm{X}$ foi reconhecida por J.J. Thomson e por W.H. 
Bragg entre 1903-1906. Boa parte da comunidade científica acreditava que os raios X eram pulsos eletromagnéticos. Após 1912, com a observação clara dos padrões de difração dos raios X, a hipótese dualista foi abandonada. É concebível, porém, que a hipótese dualista tivesse se tornado hegemônica, estendendo a dualidade para todas as formas de radiação eletromagnética. É interessante estudar também se a descoberta do raio X poderia ter sido antecipada, em função de avanços tecnológicos.

6 Descoberta da quantização por meio de Modelos Atômicos e Químicos. É concebível que o desenvolvimento de modelos atômicos, aliado aos dados espectroscópicos e à teoria química, levasse à noção de quantização. Tal via teria que ser investigada, mas ela parece improvável. É digno de nota também que a descoberta do tautomerismo (Kekulé, Butlerov, década de 1860), envolvendo por exemplo duas formas do anel de benzeno, já envolvia a noção quântica de ressonância, como mais tarde foi estabelecida por Heisenberg (1926) em sua discussão do átomo de hélio.

7 Descoberta da quantização por meio do Magnetismo. A primeira teoria quântica do magnetismo apareceu com Weiss em 1911. Após o modelo atômico de Bohr, Stern \& Gerlach conceberam o famoso experimento em que o momento magnético de um átomo neutro leva a uma quantização espacial. Poderiam as condições tecnológicas necessárias para o experimento terem sido desenvolvidas antes de 1900?

8 Descoberta da quantização de energia por meio da Teoria Cinética dos Gases. Já mencionamos a tese de N. Mott (ver nota 3 ), segundo a qual a quantização dos átomos poderia ter sido deduzida a partir da teoria cinética dos gases, da observação de que qualquer energia transferida para uma molécula monoatômica aumenta apenas sua energia cinética, e não a energia dos graus internos de liberdade. A partir das anomalias conhecidas com relação aos valores dos calores específicos de gases, Kelvin (1892) já lançava sérias dúvidas sobre a validade da lei de equipartição de energia. Podemos mencionar também o paradoxo de Gibbs (1898), relativo à entropia de misturas de gases, que só foi explicado a partir das estatísticas quânticas. Estes e outros problemas da Mecânica Estatística poderiam ter levado ao postulado quântico (afinal de contas, Planck se baseou em um método estatístico de Boltzmann para chegar a este postulado)? Com relação a esta via, alguns autores (como Rayleigh, in Jammer, 1966: 13) acreditam que se os trabalhos originais de Waterston (1845) não tivessem sido ignorados, a Teoria Cinética poderia ter sido desenvolvida dez anos antes. 
9 Descoberta da dualidade onda-partícula a partir da Analogia Mecânico-Óptica. Em 1834, W.R. Hamilton desenvolveu uma abordagem variacional tanto para a Óptica quanto para a Mecânica. A Óptica Geométrica corresponderia à Mecânica Newtoniana; e a Óptica Ondulatória, a que mecânica corresponderia ela? Poucos físicos teóricos prestaram atenção a esta analogia, mas depois do trabalho de L. de Broglie, Debye, Madelung e Schrödinger trabalharam no projeto de elaboração da Mecânica Ondulatória. Sob que condições históricas a analogia formal de Hamilton poderia ter gerado uma mecânica ondulatória, independentemente das constatações experimentais de que existe uma dualidade onda-partícula?

10 Descoberta da dualidade onda-partícula por meio do Elétron. O aspecto corpuscular do elétron foi descoberto por J.J. Thomson em 1896, e o aspecto ondulatório por seu filho G.P. Thomson (e também por Davisson \& Germer) em 1927. Teria sido possível observar o aspecto ondulatório anteriormente? Aparentemente não, mas tal conclusão precisa ser sustentada com argumentos relativos ao desenvolvimento da técnica experimental.

\section{Continuação do trabalho}

O presente projeto ainda está em seu início. O passo mais importante a ser tomado é o estudo de cada artigo individualmente, para aprofundar a análise das redes de influências causais. Atenção especial será dada para a parte experimental e tecnológica, pois estes aspectos são menosprezados pela maior parte da literatura secundária. Será também preciso desenvolver melhor as estratégias para a postulação de histórias contrafactuais, aprimorando os programas computacionais utilizados. 


\section{Apêndice}

\section{Representação dos artigos, avanços e redes de influências}

Faremos agora uma breve descrição de como a informação histórica tem sido representada nos programas computacionais elaborados.

Em nosso estudo, cada artigo relevante publicado no período é armazenado com as seguintes informações:

Quadro 1- Representação de um artigo

Nome do Artigo

\begin{tabular}{|c|c|}
\hline 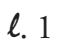 & ( (AUTOR 1 AUTOR $2 \ldots)$ \\
\hline 2 & (ANO MÊS DIA) \\
\hline 3 & "REFERÊNCIA: TÍTULO, PERIÓDICO, VOLUME, PÁGINA" \\
\hline 4 & $($ AVANÇOl AVANÇO $2 \ldots)$ \\
\hline 5 & $\begin{array}{l}(\text { ( ANTECEDENTE } 1 \text { ANTECEDENTE } 2 \ldots \\
(\text { ANTECEDENTE-DISCORDANTE } 1 \ldots) \text {...) }\end{array}$ \\
\hline 6 & TIPO-DE-ARTIGO \\
\hline
\end{tabular}

Na linguagem SCHEME (assim como em LisP), tudo é representado por meio de "listas", que são delimitadas por parênteses. Um artigo é representado por uma lista contendo seis elementos, alguns dos quais são outras listas.

Tomemos como exemplo de artigo aquele de nome Wien1896. Seu autor é identificado como (WIEN). A expressão WIEN, em nosso programa, não é meramente um nome, mas se refere a uma outra lista contendo várias informações relevantes sobre o autor, como anos e locais de trabalho, professores, colegas de trabalho, conferências assistidas etc. No futuro, poderemos usar esse tipo de informação para aprimorar o estudo das redes de influência (o programa poderá avaliar, por exemplo, se um avanço pode ter passado de um cientista para outro por via oral, caso eles tenham se encontrado em uma universidade ou em uma conferência).

Voltemos ao artigo Wien1896. A segunda linha (ver quadro 1) informa que o artigo foi publicado em (1896 07), ou seja, em julho de 1896. A linha seguinte fornece uma referência resumida do artigo, que permita sua localização em uma biblioteca.

Passemos agora para três itens importantes: os avanços, os antecedentes e o tipo de artigo. Comecemos pelo último. O tipo de artigo explicita se o trabalho é experimental ou teórico, se se trata de uma resenha, uma coleta de dados, uma carta, um trabalho matemático ou de desenvolvimento de aparelhagem etc. No 
presente exemplo, trata-se de uma Descoberta Teórica. No quadro 2 apresentamos os tipos de artigos utilizados.

Quadro 2 - Tipos de artigos

\begin{tabular}{|ll|}
\hline EXPERIMENTAL & TEÓRICO \\
TÉCNICO EXPERIMENTAL & MATEMÁTICO \\
DESCOBERTA EXPERIMENTAL & DESCOBERTA TEÓRICA \\
DADOS EXPERIMENTAIS & RESENHA DE ARTIGO \\
RESENHA EXPERIMENTAL-TEÓRICA & RESENHA TEÓRICA \\
CRÍTICA EXPERIMENTAL & CRÍTICA TEÓRICA \\
\hline
\end{tabular}

Os antecedentes de um artigo (linha 5 do quadro 1 ) consistem em trabalhos que o influenciaram diretamente (de maneira forte ou fraca). Até o presente estágio do projeto, os antecedentes que anotamos são aqueles indicados pela literatura secundária. No caso de Wien 1896, os antecedentes anotados são Maxw1860 (Maxwell), Lomml878 (Lommel), MicV1887 (V. Michelson), Wienl894 e Lumm 1895 (Lummer \& Wien). Posteriormente, quando examinarmos cada artigo individualmente, anotaremos todas as citações presentes no artigo, o que tornará a rede de influências bem mais complicada do que a que obtivemos até aqui.

A figura 1 exibe um resumo da rede de influências entre artigos para a área de Radiação Térmica, que inclui o artigo de Wien. O retângulo correspondente ao artigo pode ser encontrado acompanhando o eixo temporal (horizontal) até o ano de 1896. O eixo vertical está dividido em cinco grandes tipos de artigos, correspondendo ao eixo R-T mencionado na seção Tipos de avanços. O artigo Wienl896 encontra-se no meio, na região das leis empíricas. Notamos que ela recebe três setas, de Lomm1878, Wien1894 e Lumm1895; as outras duas influências mencionadas anteriormente não estão indicadas explicitamente porque elas também influenciaram Wienl894, antecedente de WiEN1896.

Notamos que cinco setas saem de Wien1896, o que indica que pelo menos cinco outros artigos são por ele influenciados. Três destas setas possuem bolinhas em suas origens. Bolinhas negras indicam que o artigo influenciado, no caso LumM 1899b (Lummer \& Pringsheim), contradiz o avanço feito por Wienl896: neste caso, Lummer \& Pringsheim mostraram que dados experimentais no infravermelho não obedecem à lei de radiação proposta por Wien. Este é um exemplo de um antecedente discordante, que na lista representativa do artigo (quadro 1 , linha 5) é colocado lado-a-lado com antecedentes concordantes, mas dentro de parênteses adicionais. Na figura $\mathrm{l}$, a bolinha branca indica uma concordância entre o artigo original e sua influência, especialmente quando dados experimentais corroboram uma lei; em geral, quando não há bolinhas na seta, temos uma influência concordante. 
Aproveitando que estamos falando sobre Wien1896, notamos uma linha tracejada (com bolinhas brancas) entre este artigo e PAsc1896 (Paschen). Esta notação indica que o mesmo avanço foi obtido independentemente, constituindo uma descoberta independente. No quadro 1 não existe indicação de descobertas independentes. No entanto, escrevemos uma rotina (chamada Find-Discovery) que fornece todos os artigos que tenham obtido um avanço de maneira independente. Assim, por exemplo, ao perguntarmos quem obteve a Lei de Radiação de Wien de maneira independente (da lista de todos os artigos anotados, lista esta que chamamos de ART-ALL), obtemos a seguinte resposta (após a seta): (FIND-DisCOverY Wiens_Radiation_LaW Art-All) $\rightarrow$ (Pasc1896 Wien1896).

Para finalizar a descrição do quadro 1 , a linha 4 apresenta os avanços obtidos no artigo em questão. A figura 2 apresenta a rede de influências entre avanços no caso da Radiação Térmica. Ela corresponde à rede entre artigos apresentada na figura 1, mas envolve apenas idéias, dados experimentais, leis etc., sem fazer referência aos artigos nos quais apareceram ou aos cientistas responsáveis por eles. Dados experimentais, por exemplo, normalmente vêm acompanhados dos nomes dos cientistas que os obtiveram, mas na rede de influência entre avanços eles devem ser pensados como um conjunto de dados disponíveis na literatura (independente de quem os obteve), dados estes que são concatenados (pelos cientistas) com outros avanços, tendo em vista a geração de novos avanços.

Um avanço chega ao conhecimento de um cientista por diversos meios. Neste trabalho, estamos priorizando os avanços disponíveis nos artigos publicados. Outros meios, como livros didáticos, que têm um papel importante na transmissão dos avanços consagrados da ciência, e a comunicação pessoal entre os cientistas também poderão ser incorporados posteriormente.

Para o artigo WIEN1896, os dois avanços mais relevantes são apresentados na seguinte lista (linha 4 do quadro 1): (PROBLEMA_DA_LEI_DE_RADIAÇÃO LEI_DE_RADIAÇÃO_DE_WIEN). A definição de cada um destes avanços é por sua vez dada por meio de uma outra lista. Representamos um avanço por meio de uma lista com três elementos (quadro 3):

Quadro 3 - Representação de um avanço

Nome do Avanço

\begin{tabular}{|c|c|}
\hline ८. 1 & ( "EnUNCIADO DO Avanço" \\
\hline 2 & ( ( INFluÊNCIA-Fortel InfluÊNCIA-Forte $2 \ldots$...) \\
\hline & (INFluênCIA-Fracal InfluênCIA-Fraca2 ...) ) \\
\hline 3 & TIPO-DE-AVANÇO \\
\hline
\end{tabular}


O "enunciado" explica o avanço, em três ou quatro linhas. A segunda linha traz informação sobre as influências causais que levaram ao avanço. Esta lista é composta dos dois tipos quantitativos de influência causal, discutidos na seção Tipo de influência causal. As distinções qualitativas envolvendo diferentes classes de avanços não precisam ser representadas explicitamente, podendo ser encontradas por meio de uma rotina computacional. Na figura 2, representamos apenas um tipo qualitativo de influência, aquele entre uma lei empírica e os dados experimentais (setas com traços e pontos), geralmente classificado quantitativamente como influência forte.

O avanço LEI_DE_RADIAÇÃO_DE_WIEN localiza-se, na figura 2, no mesmo local em que encontramos Wien 1896 na figura 1. Mantivemos na figura 2 as bolinhas brancas e pretas, mas esta informação não faz parte da representação dos avanços (quadro 3). Notamos que duas setas paralelas atingem o avanço LEI_DE_RADIAÇÃO_DE_WIEN (uma forte e uma fraca), exprimindo duas histórias possíveis (pois esta lei foi descoberta independentemente por Wien e Paschen, e o avançO GERAÇÃO_DE_RADIAÇÃO_DE_CORPO_NEGRO_ISOTÉRMICO influenciou o primeiro fracamente, e o segundo fortemente).

Outro avanço digno de nota é o chamado SEMELHANÇA_ENTRE_InJ_E_S, notado por Planck em PLAN1900f. Foi ao perceber uma semelhança formal entre a expressão que obteve para a entropia quântica de osciladores, de um lado, e a medida de permutação para valores discretos de energia de Boltzmann, de outro, que Planck encontrou a chave para a derivação de sua lei de radiação a partir de primeiros princípios. O avanço mencionado é um passo heurístico para reunir a ENTROPIA_QUÂNTICA_DE_OSCILADORES e a MEDIDA_DE_PERMUTAÇÃO e conseguir obter a DERIVAÇÃO_DA_LEI_DE_PLANCK. Esse avanço poderia ter sido omitido da figura (nota-se a maneira especial em que é desenhado), mas eu quis salientar a importância deste tipo de avanço, chamado SemelHança matemática (presente no quadro 4, a seguir), para as descobertas pioneiras da Física Quântica - ela também esteve presente na obtenção da hipótese do quantum de luz por Einstein, ao comparar a expressão da entropia dos osciladores da lei de Wien com a da entropia do gás ideal.

A última linha do quadro 3 é o "tipo de avanço", que pode ser um dentre os vários que estão listados no quadro 4 (ver discussão na seção Tipos de avanços). 
Quadro 4 - Tipos de avanços usados, divididos de acordo com sua classe

COMPARAÇÃO

DADOS-TEORIA

CÁlculo de constante

CÁlculo de Fenômeno

DADOS CONCORDAM COM TEORIA

DADOS TESTE CRUCIAL

DADOS DISCORDAM DA TEORIA

IMPLEMENTAÇÃO EXPERIMENTAL

\section{CONCEITOS \&} DEFINIÇÕES

CONCEPÇão TEÓRICA

Definição de ObJeto

DeFinição TeÓRICA

Distinção TEÓRICA

ENUNCIADO DE PARADIGMA

IDENTIFICAÇÃO TEÓRICA

Modelo para Análise

\section{DADOS}

EXPERIMENTAIS

Dados EXPLORATÓRIOS

Dados negativos

Dados ReconfirmaÇÃo

Dados SISTEMÁticos

\section{DESENVOLVIMENTO DA TEORIA}

AMPLIAÇÃO DE DOMÍNIO

EXTENSÃO DE TEORIA

Restrição DE DOMÍNIO

Teoria geral

TeOria RUdimentar

\section{EXPLICAÇÕES}

EXPLICAÇÃO DE ANOMALIA

EXPLICAÇÃO DE LEI

EXPLICAÇÃO DE MECANISMO

EXPLICAÇÃO DE NATUREZA

EXPLICAÇÃO NÃO ADHOC

EXPLICAÇ̃̃o TEÓRICA

Modelo REPRESENTACIONAL

\section{LEIS \& FATOS}

EXPLORAÇÃo DE FENÔMENO

FATO INFERIDO

FATO OBSERVADO

LEI CORRELATIVA

LEI EMPÍRICA

Lei Matemática

Lei Teórica

PRINCíPIO EMPíRICO

Princípio geral

Princí́pio teórico

Regularidade

Semelhança OBSERVACIONAL

\section{MOTIVAÇÃO\& VALORES}

Motivação

\section{PROBLEMAS \& CRÍTICAS}

AnOMalia teórica CRÍtICA EXPERIMENTAL Crítica teórica

Problema de EXPLICAÇ̃̃o

Problema EXPERIMENTAL

Problema NOMOLÓgico

Problema teórico

\section{TÉCNICA EXPERIMENTAL}

ANALISADOR EXPERIMENTAL

FonTE EXPERIMENTAL Detector exPeRIMENTAL INSTRUMENTO EXPERIMENTAL MÉTODO EXPERIMENTAL VARIAÇÃO EXPERIMENTAL

TRABALHO TEÓRICO

Analogia teórica CONCORDÂNCIA INTERTEÓRICA DERIVAÇÃo TEÓRICA EXPLORAÇÃO TEÓRICA Método teórico SeMELHANÇA MATEMÁtica SUPOSIÇÃo TEÓRICA 
Notas

1 Outra motivação para se estudarem as histórias possíveis está no Ensino de Ciência. Pode-se argumentar que um curso de introdução à Física Quântica não deve se ater aos tortuosos caminhos da história da área, mas sim partir de experimentos simples que só puderam ser realizados nos últimos 20 anos. Mas se quisermos nos ater à abordagem histórica, somos obrigados a nos restringir ao caminho que de fato ocorreu em nossa civilização, mesmo sabendo que este caminho era "improvável"? Não poderíamos fazer uso das histórias possíveis que não se realizaram, como forma de encontrar maneiras mais didáticas de ensinar Física?

2 Para esclarecer um pouco mais esta questão, considere o método usado pela Física, por exemplo, para determinar as causas de um fenômeno. O método científico, simplificadamente, consistiria em primeiro controlar diferentes parâmetros (temperatura, pressão etc.) até atingir uma situação em que o sistema se comporta de maneira previsível. Aí, passa-se a variar uma das condições (temperatura, por exemplo), mantendo-se os outros parâmetros fixos, e a observar o comportamento do sistema. Ora, cada experimento para um dado conjunto de valores dos parâmetros pode ser encarado como a realização ("emulação") de uma história possível. Após o término da investigação, elabora-se uma teoria para o fenômeno, e sempre que o fenômeno for observado na natureza, pode-se dizer: "A causa para este fenômeno é o fato dos parâmetros terem tais valores." Claramente, está implícito que se os valores dos parâmetros (as causas) fossem outros (histórias contrafactuais!), o fenômeno observado teria outras características.

Em Física, as causas podem ser controladas. Em ciências como a Astronomia, o que permite descobrir as causas (da explosão de uma estrela, por exemplo) é a existência de muitas cópias dos mesmos sistemas, cada qual com parâmetros (tamanho, idade) diferentes. O conjunto das estrelas observadas fornece um mapa das histórias possíveis que uma dada estrela recém-descoberta pode seguir. Por outro lado, numa ciência histórica, como a Geologia do século XIX, ocorre o agravante de só haver um único sistema a ser observado. Assim, o mapeamento das causas é feito com muito mais dificuldade. Felizmente, para a Geologia, o estudo geológico dos outros planetas de nosso sistema solar tem lançado muita luz sobre as causas em Geologia. Para a História da Ciência, porém, só temos acesso a uma das histórias possíveis, aquela que de fato ocorreu (exceções ocorrem nos casos de descobertas simultâneas).

3 Além da história que de fato ocorreu, pelo menos quatro outros caminhos para partes da Teoria Quântica Velha são sugeridos. 1) Espectroscopia. Apenas a partir do estudo das raias dos espectros característicos de cada substância, poderse-ia ter chegado não só à noção de quantização de energia mas até ao princípio de correspondência e à mecânica matricial. 2) Átomo. O estudo da estrutura atômica e das propriedades químicas dos átomos poderia ter levado 
independentemente ao princípio de exclusão de Pauli. 3) Estatística. Considerações sobre o comportamento térmico de corpos a baixas temperaturas poderiam ter levado à constante de Planck, e desenvolvimentos estatísticos ulteriores poderiam ter levado a uma parte considerável da Física Quântica, especialmente em conjunção com a espectroscopia. 4) Dualidade. A proporcionalidade entre E e v para a luz já estava presente no trabalho de Wien (1897), o que poderia ter levado Einstein à concepção corpuscular da luz independentemente de Planck. A partir da dualidade da luz, poder-se-ia ter chegado à dualidade da matéria. Com relação ao item 3, Nevill Mott (1964) argumentou que a quantização dos átomos poderia ter sido deduzida a partir da teoria cinética dos gases, da observação de que qualquer energia transferida para uma molécula monoatômica aumenta apenas sua energia cinética, e não a energia dos graus internos de liberdade.

4 Pode-se criticar esta abordagem salientando que o significado de um avanço, por exemplo um conceito, pode depender fortemente de seu contexto teórico, de forma que não seria válido supor que o avanço "se conserva" perfeitamente de uma história para outra. Sem saber como tratar esta questão, prefiro levar a cabo o projeto proposto para, ao final, examinar os resultados e ver que luzes podem ser lançadas no problema.

5 Uma importante classe de influência causal na ciência são os CONDICIONANTES SOCIAIS. Por exemplo, a decisão dos governos europeus de investir em ciência teve um papel fundamental no surgimento da Física Quântica. Tais condicionantes se refletem na mente dos cientistas na forma de MOTIVAÇÕES \& VALORES. Os condicionantes sociais não são propriamente "avanços", mas desempenham um papel de importância comparável ao dos avanços para explicar o desenvolvimento da ciência (traçamos aqui a distinção clássica entre relatos internalistas e externalistas na História da Ciência). Deixarei em aberto o problema da descrição destes condicionantes sociais e de sua relação com os avanços.

6 É preciso deixar bem claro o que se entende por probabilidade de uma história possível. Quais seriam as probabilidades de ocorrência das diferentes vias traçadas na seção anterior? Para responder a esta pergunta, é preciso partir de um estado particular, por exemplo, o estado das ciências físicas no ano de 1800. Imaginemos que, nesse ano, mil cópias idênticas do Sistema Solar fossem feitas (incluindo a Terra e seus habitantes), e cada cópia fosse separada da outra e espalhada pela Via Láctea. Quais teriam sido as histórias percorridas, supondo-se que a evolução destes sistemas não fosse estritamente determinista (pequenas variações no ambiente em torno de cada sistema solar levariam progressivamente a uma diferenciação entre eles)? Estamos inquirindo sobre uma "probabilidade condicional": qual a probabilidade de ocorrerem diferentes histórias $H_{i}$ dado que o estado $S_{1800}$ tenha previamente existido? Esta pergunta, porém, tem um elemento adicional: queremos saber as probabilidades de se ter chegado à Física Quântica, ou seja, a um estado da ciência $S_{j}$ dentro de uma classe de estados na 
qual a Física Quântica tenha sido estabelecida: $\left\{S_{j}\right\}_{\mathrm{FQ}}$ (ou seja, desprezamos aqueles mundos contrafactuais nos quais cataclismas tenham impedido o surgimento da Física Quântica). Queremos então uma probabilidade condicional em $S_{1800}$ e $\left\{S_{j}\right\}_{\mathrm{FQ}}$.

\section{Referências bibliográficas}

BRUSH, S.G. The kind of motion we call heat - A history of the kinetic theory of gases in the 19th century. Amsterdã, North-Holland, 1976.

FEIGL, H. The 'orthodox' view of theories: remarks in defense as well as critique, in Radner, M. \& Winokur, S. (orgs.), Analyses of theories and methods of Physics and Psychology (Minnesota Studies in the Philosophy of Science IV). Minneapolis, University of Minnesota Press, 1970, p. 3-16.

HAWTHORN, G. Plausible worlds - Possibility and understanding in history and the social sciences. Cambridge, Cambridge University Press, 1970.

HENTSCHEL, K. The interplay of instrumentation, experiment, and theory: patterns emerging from case studies on solar redshift, 1890-1960. Philosophy of Science v.64, Proceedings: S53-S64, 1997.

HOLTON, G.; CHANG, H. \& JURKOWITZ, E. How a scientific discovery is made: a case history. American Scientist n. 84, p. 364-375, 1996.

HULL, D. Science as process. Chicago, University of Chicago Press, 1988.

HUND, F. Paths to quantum theory historically viewed, Physics Today, v. 19, n. 8 , p. 23-29, 1966.

JAMMER, M. The conceptual development of quantum mechanics. Nova Iorque, McGraw-Hill, 1966.

LAUDAN, L.; DONOVAN, A.; LAUDAN, R.; BARKER, P.; BROWN, H.; LEPLIN, J.; THAGARD, P. \& WYKSTRA, S. Mudança científica: modelos filosóficos e pesquisa histórica, Estudos Avançados, v. 19, p. 7-90, 1993. Original em inglês publicado em Synthese, v. 69, p. 141-223, 1986.

LEWIS, D. Causation. Journal of Philosophy, v. 70, p. 556-567, 1973.

MEHRA, J. \& RECHENBERG, H. The historical development of quantum theory, v. 1. Nova Iorque, Springer, 1982.

MOTT, N. On teaching quantum phenomena. Contemporary Physics, v. 5, p. 401-418, 1964.

THAGARD, P. Computational philosophy of science. Cambridge, MIT Press, 1988. 
RESUMO - NESTE artigo procura-se desenvolver um método para investigar histórias contrafactuais da ciência, isto é, histórias possíveis que não se realizaram. Desenvolvemos uma teoria da ciência baseada na noção de "avanço" (idéias, dados etc.), que são unidades passadas de cientista para cientista e que se conservariam na passagem de uma história possível para outra. Os avanços estão ligados entre si por redes de influência causal, distinguindo-se influências fortes e fracas. Dezenas de tipos de avanços são agrupadas em dez classes. Como estudo de caso, examinamos o surgimento da Física Quântica Velha (1850-1915), utilizando a computação para armazenar e processar as informações históricas. Baseados apenas na literatura secundária, descrevemos quatro grandes histórias possíveis e seis pequenas vias para o surgimento desta teoria. Como continuação do trabalho, teremos que examinar com mais detalhe a história do período, especialmente da ciência experimental, e aprimorar as estratégias para a postulação de histórias contrafactuais.

ABSTRACT - IN THIS paper, one attempts to develop a method for investigating counterfactual histories of science, that is, possibles histories that did not occur. We develop a theory of science based on the notion of "advance" (ideas, data etc.), which are units passed from scientist to scientist and which would be conserved in passing from one possible history to another. Advances are connected to each other by nets of causal influence, and we distinguish strong and weak influences. Around sixty types of advances are grouped in ten classes. As our case study, we examine the beginning of the Old Quantum Theory (1850-1915), using computation to store and process historical information. Based only on secondary literature, we describe four great possible histories and six small paths to the appearance of this theory. As continuation of the research, we will have to examine in greater detail the history of the period, especially of experimental science, and improve the strategies for postulation of counterfactual histories.

Osvaldo Pessoa Jr. fez seu doutorado em História e Filosofia da Ciência na Indiana University (1990). Foi durante dois anos (1997-98) professor visitante no Instituto de Estudos Avançados da USP, quando realizou a maior parte da presente pesquisa. Atualmente ele participa do Programa Interdisciplinar sobre Ciência e Educação (UFBa/UEFS), sendo professor visitante do Instituto de Física da Universidade Federal da Bahia.

O autor agradece o apoio dado pelo Instituto de Estudos Avançados da USP e pelo Instituto de Física da UFBa, sem o qual este trabalho permaneceria contrafactual. Gostaria também de agradecer os comentários e incentivo dado pelos pesquisadores do Mestrado Interunidades de Ensino de Ciências (USP), do Grupo de Lógica e Teoria da Ciência (FFLCH-USP) e do Programa Interdisciplinar sobre Ciência e Educação (UFBa), especialmente Felippe Serpa, João Carlos Salles, Julio Vasconcelos e Olival Freire Jr.. 